\title{
Welsh dentists take on educational roles to enhance patient care
}

A new initiative launched six months ago has seen 58 dentists across Wales take on roles in education and training to enhance patient services in their practices.

Dentists who attend Health Education and Improvement Wales's (HEIW's) Making Prevention Work in Practice (MPWiP) training course are equipped to teach dental nurses how to give preventive care advice to patients and the application of fluoride varnish.

Kirstie Moons, Associate Director for Dental Team Workforce Planning and Development at HEIW, said: 'MPWiP provides a unique opportunity for dental teams to deliver optimum patient care focusing on prevention as set out in Welsh Government's long-term plan 'A Healthier Wales - the Oral and Dental Services Response'.

'The course enables dentists to become educational trainers, training their dental nurses in the workplace using current clinical evidence for preventive care.

'Following completion of the course, each dentist will go onto train three or four dental nurses, meaning the potential impact of this ripple effect model of training is huge.'

Research suggests that as much as $73 \%$ of treatment in general dental practices could be carried out by DCPs - dental nurses, hygienists, therapists, and technicians. Training dental nurses to provide effective self-care instructions to patients and to apply fluoride varnish will give dentists more time to provide advanced care to patients with more complex needs.

\section{BOOK REVIEW}

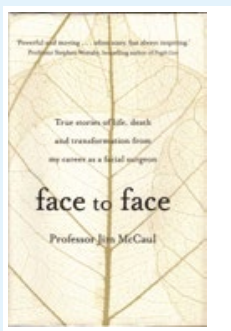

\section{FACE TO FACE: TRUE STORIES OF LIFE, DEATH AND TRANSFORMATION FROM MY CAREER AS A FACIAL SURGEON}

Jim McCaul;

2018; Bantam Press; price £16.99 pp. 320

ISBN: 9780593079119

'Like most people, I know little about the specialist branches of medicine until I come to need them, usually at short notice. So it was with maxillofacial surgery and the people who practise it - we are truly lucky to have them. These are the words of Martin Bell, a war correspondent who evaded bullets and mortars during his distinguished career, only to sustain serious facial injuries after tripping over his suitcase, thereby requiring reconstructive surgery by maxillofacial surgeons.

Perhaps Professor Jim McCaul's book, Face to face: true stories of life, death and transformation from my career as a facial surgeon will help to raise the profile of the speciality to this end. Medical non-fiction with an autobiographical element, particularly from surgeons, has been devoured by the public and enjoys a broad readership. Pioneering authors, such as Henry Marsh and Atul Gawande, have offered enthralling and refreshingly honest detours into their respective fields of work.

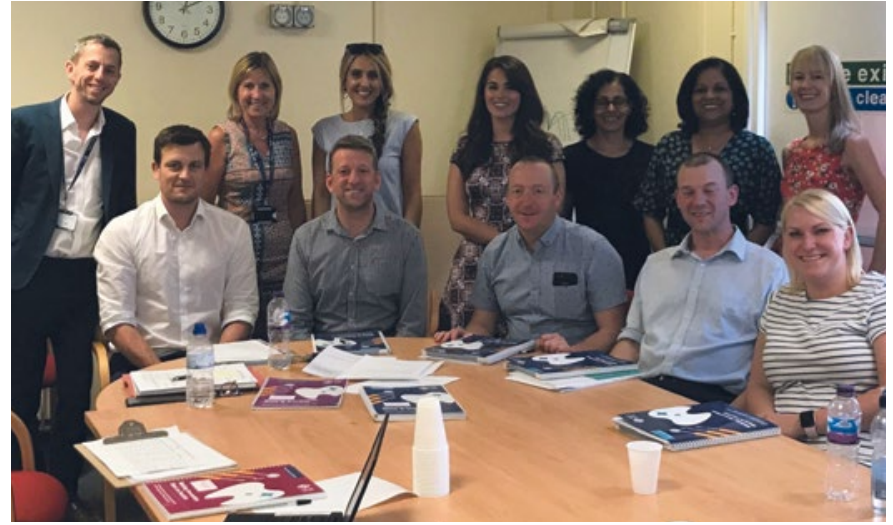

A group of ten dentists on the Making Prevention Work in Practice training course with their HEIW trainers Adam Porter and Jane Norgate

Dr Jeremy Williams, a dentist at Rosehill Dental Practice in Conwy, said: 'We have found the MPWiP course the perfect way to deliver training to our dental nurses to increase their skills and knowledge. Training in-house means it is much easier to build time for the delivery of the course and the supervision of the prevention advice and fluoride applications into a busy NHS practice.'

The next Making Prevention Work in Practice courses for dentists will be held on 19 September 2019 (Swansea) and 22 October 2019 (Rhyl). For more information, visit https://www.maxcourse.co.uk/ walesdent/guestHome.asp.

Now, a little closer to home, Professor McCaul invites us to the world of oral and maxillofacial surgery, delving into the extraordinary stories of individuals requiring extensive and life-changing work. He recalls both the technically fascinating aspects of the surgeries, as well as the personal stories of the individuals involved, probing into the psychological side of working on an area of the body arguably most intimately associated with our sense of identity.

He explores the history of the speciality and the methods pioneered by Harold Gillies during the First World War as well as the future and where we may expect technological and research innovations to take us.

The book is tastefully peppered with the author's own personal journey through the speciality, from his time as a dental student all through his lengthy training as he pursues his passion, recalling the challenges and opportunities he comes across along the way. It is during a travelling fellowship that the author experiences healthcare in the USA, reflecting on an instance where he is unable to prescribe analgesia for a patient before her major surgery, simply because her insurance does not cover it. Such alarming stories may offer a different angle on a more privatised healthcare system as currently advocated by some.

Overall, the book, written with great insight and humanity, would be of interest to those working within healthcare as well as to the general public for its uniquely gripping look into the speciality.

Roxanne Mehdizadeh 